\title{
Os Impactos da Reforma Trabalhista para o Trabalhador, Empresas e Sindicatos: Uma análise da lei 13.467/2017
}

\author{
Júlia Pottumati Nogueira Abdala \\ Centro Universitário Farias Brito, Fortaleza, CE, Brasil \\ Mauricio Johnny Loos \\ Centro Universitário Farias Brito, Fortaleza, CE, Brasil
}

\begin{tabular}{c} 
Received 9 fev. $19 ;$ Accepted 16 jul. 19 \\
Evaluation System: Double Blind Review \\
Editor: Jose Lindenberg Julião Xavier Filho, Dr. \\
ISSN: 2594-8040 \\
\hline
\end{tabular}

To cite this paper: Abdala, J. O. N. \& Loos, M. J. (2019). Os impactos da reforma trabalhista para o trabalhador, empresas e sindicatos: Uma análise da lei 13.467/2017. Journal of Perspectives in Management - JPM, 3(1), p. 29-40.

\section{Resumo}

O presente trabalho tem por escopo fazer uma análise acerca dos impactos da reforma trabalhista promovida pela Lei 13.467/17, para o trabalhador, empresas e sindicatos. Para tanto se utiliza do método lógico-dedutivo com respaldo em correntes doutrinárias e jurisprudências sobre o tema. Impactos serão considerados enquanto repercussões de ordem legal, social e econômica; trabalhador, como indivíduo que presta serviço de forma esporádica a terceiro e mediante pagamento; empresas, como as atividades econômico-sociais exercidas pelo empresário, consoante a reunião de elementos humanos, materiais e técnicos, e sindicatos como associação que reúne indivíduos de um mesmo segmento econômico ou trabalhista. Ao alterar a Consolidação das Leis Trabalhistas (CLT), com vistas à modernização e flexibilização das relações de trabalho no Brasil, a Lei 13.467 produziu impactos desfavoráveis aos trabalhadores e sindicatos e favoráveis as empresas, quando pelas liberalidades concedidas as partes possibilitaram que o pactuado se sobrepusesse a lei, acarretando a supressão de direitos e garantias legalmente previstos, bem como constituindo verdadeiro retrocesso a legislação trabalhista. Os resultados do trabalho mostram que a prevalência do negociado entre patrão e empregado em detrimento da lei e a perda do poder dos sindicatos na proteção dos trabalhadores sujeitam a classe trabalhadora e os sindicatos ao poderio capital pertencente aos empregadores, sem de fato modernizá-la as exigências sociais as quais o Brasil anseia.

Palavras-Chave: Modernização das relações de trabalho. Consolidação das Leis trabalhistas. Flexibilização. Direitos sociais. Dignidade humana. 


\section{Introdução}

Em meio a argumentos de atualização legislativa e entraves à manutenção das relações de trabalho no Brasil, a Lei 13.467, de 13 de julho de 2017, denominada de "reforma trabalhista", viria a promover a partir de novembro de 2017, profundas alterações no bojo da Consolidação das Leis Trabalhistas (CLT), dividindo os estudiosos quanto à produção de efeitos positivos e negativos da legislação.

De alterações simples como a previsão de novas formas de contratação até a facultatividade da contribuição sindical pelos trabalhadores, alguns impactos legais, sociais e econômicos significativos no dia-a-dia do trabalhador, das empresas e dos sindicatos brasileiros seriam vislumbrados merecendo um estudo pormenorizado de diferentes áreas da ciência que não apenas a jurídica.

Neste diapasão, o presente trabalho sem a intenção de esgotar a problemática, se propõe a analisar a temática em três capítulos: no primeiro deles, tratando da modernização das leis trabalhistas e do contexto de inserção da reforma trabalhista, com destaque ao contexto histórico das relações de trabalho no Brasil e dos direitos assegurados no bojo da Constituição Federal de 1988, e da Consolidação das leis Trabalhistas. Ainda, das críticas, contradições e argumentos favoráveis a inserção da Lei 13.467, de 13 de Julho de 2017, e, por fim, dos impactos promovidos pela reforma em face do trabalhador, das empresas e sindicatos.

No segundo capítulo, dos procedimentos metodológicos utilizados para a consecução dos fins almejados pela pesquisa, e, no último, da apresentação e discussão dos resultados.

Afinal, os impactos promovidos pela referida reforma são favoráveis a classe trabalhadora? E as empresas e sindicatos? Há retrocesso ou inovações na seara trabalhista?

\section{Revisão de Literatura}

\subsection{Breve retrospecto Histórico das Relações de Trabalho e dos Direitos Trabalhistas no Brasil}

Considerando que o presente trabalho tem por objetivo fazer uma análise acerca dos impactos da reforma trabalhista para o trabalhador, empresas e sindicatos, é oportuno que inicialmente seja feito um breve retrospecto histórico das relações de trabalho e dos direitos trabalhistas no Brasil.

E em que pese o marco histórico das relações trabalhistas e dos direitos por elas abarcados tenham surgido com a promulgação da Lei Áurea editada pela princesa Isabel em 13 de Maio de 1888, que dentre outros efeitos aboliria a escravatura do seio social, seu desenvolvimento propriamente dito é atribuído a Era Vargas e ao processo de imigração.

Para Costa (2015), em analisando o contexto histórico das relações de trabalho no Brasil é possível destacar três diferentes fases: a pré-histórica, a história e a contemporânea. A primeira desenvolvida a partir da independência do Brasil até a abolição da escravatura e na qual não há de se falar em direitos do trabalhador; a segunda, da abolição até o ano de 1930, com o surgimento dos primeiros documentos legais e, a terceira, de 1930 até os dias atuais, fase de constitucionalização da esfera trabalhista.

Comentando a fase pré-histórica, Andrighetto (2009) em consonância a doutrina trabalhista moderna ressalta que muito embora se tente formar um marco inicial para a ciência trabalhista antes do século XIX, não há fundamentos que o permitam, visto que ela se resumia as transcrições feitas nas primeiras constituições, a exemplo, na Carta de 1824, quando mencionava a abolição das 
corporações de ofício pela necessidade de liberdade das profissões, mas mantinha no seio social a prática da escravatura.

$\mathrm{Na}$ Constituição republicana de 1891, é reconhecida pela primeira vez a liberdade de associação e reunião pacífica, sendo a partir de então editadas inúmeras leis tendentes a regulamentar os direitos trabalhistas, embora não houvesse ainda uma solidificação dos institutos. Cita-se neste ínterim a edição dos decretos 1.162/1890, que previu como ilícito penal a greve; e do 1.313, do mesmo ano, que regulamentou o acidente de trabalho e alguns conceitos básicos. (Andrighetto, 2009).

Observe que não obstante a presença de inúmeras legislações de cunho eminentemente trabalhista os direitos do trabalhador propriamente ditos só seriam positivados em 1930, quando por influência da Primeira Guerra Mundial e da Constituição de 1934, que incluindo um rol de garantias e direitos da classe operária fomentaria também a criação de juntas de conciliação e julgamento e a figura do órgão do Ministério do trabalho, indústria e comércio. Esses direitos e garantias juntamente com outras leis esparsas seriam reunidos na forma de uma Consolidação de leis trabalhistas no ano de 1943, objeto de análise em capítulo posterior.

Neste diapasão, Silva (2012), afirma que a primeira Constituição brasileira que tratou especificamente do direito do trabalho foi a de 1934, versando basicamente sobre a organização dos sindicatos, o caráter nacional do trabalho, a isonomia salarial, o salário mínimo, a jornada de oito horas de trabalho, a proteção ao trabalho das mulheres e dos menores, o repouso semanal, as férias anuais remuneradas, os acidentes de trabalho, as convenções coletivas e a Justiça do Trabalho.

Assim, o breve retrospecto histórico das relações de trabalho e dos direitos trabalhistas no Brasil salienta que o desenvolvimento do Direito do Trabalho só ocorre após a constitucionalização do direito em 1934, embora tenha a abolição da escravidão como precedente.

\subsubsection{Os Direitos Trabalhistas na Constituição Federal de 1988}

Perpassado o breve retrospecto histórico das relações de trabalho e dos direitos trabalhistas no Brasil, observáveis a partir da abolição da escravatura no ano de 1888, neste capítulo, serão tratados dos direitos trabalhistas na Constituição Federal de 1988.

Para Silva (2012), ao tutelar a proteção ao trabalho de forma ampla, dada a expressão em seus artigos $7^{\circ}$ ao $11^{\circ}$, no rol dos direitos sociais, a Constituição de 1988 , teria por escopo assegurar as condições mínimas de trabalho a classe trabalhadora brasileira.

$\mathrm{Na}$ concepção de Ceneviva (2003), longe de ser exaustivo o texto constitucional quis acentuar a importância dos direitos e garantias para a comunidade em geral, enquanto direitos fundamentais assegurados constitucionalmente e inerentes à condição humana.

E é neste sentido que se destaca a enumeração de inúmeros direitos dos trabalhadores urbanos e rurais, concernentes à jornada de trabalho, horas extras, décimo terceiro salário, seguro desemprego, férias, garantia de irredutibilidade do salário, entre outros.

Frise-se que diferente da Constituição de 1934, salientada anteriormente, na Constituição de 1988, o constituinte para além de assegurar aos direitos trabalhistas um "status constitucional" que obrigasse o Estado e os particulares ao seu respeito e implementação, objetivou igualmente transcrever rol de direitos essenciais ao desenvolvimento do trabalho com vistas à manutenção da vida e dignidade do trabalhador e comunidade.

Assim, os direitos trabalhistas na Constituição de 1988, ressaltam a constitucionalização do direito do trabalho e um rol de direitos fundamentais do trabalhador que objetivam o respeito a sua dignidade enquanto ser humano. 


\subsubsection{A Consolidação das Leis Trabalhistas e os Direitos Trabalhistas}

Comentados os direitos trabalhistas na Constituição Federal de 1988, sobretudo, a preocupação do legislador constituinte em garantir rol extensivo de direitos à classe trabalhadora, a seguir, será tratada a Consolidação das Leis Trabalhistas e os Direitos trabalhistas.

E não obstante tenha sido transcrito anteriormente que a Consolidação das Leis Trabalhistas surgiu em 1943, para unificar as leis do Direito do Trabalho incluídas na Constituição de 1934, e leis esparsas editadas durante o período de governo de Getúlio Vargas, seu estudo é de extrema importância para a compreensão do desenvolvimento do direito do trabalho no Brasil, sobretudo, pela política atribuída a Era Vargas que carente de leis e direitos possibilitaria ao Estado o exercício do papel de árbitro das relações entre capital e trabalho.

Para Marques (2013), o grande mérito da CLT foi unificar o direito trabalhista instalando uma regra geral para todos os trabalhadores indistintamente, pondo fim aquelas regras que tutelavam segmentos operários apartadamente, a exemplo, a coletânea dos comerciários e industriáveis.

Na visão de Silva (2012), a transcrição da consolidação foi um importante marco normativo do trabalho na medida em que trouxe uma maior segurança jurídica às relações de trabalho naquele momento histórico e permitiu a expansão do trabalho livre, remunerado e subordinado mediante as regras próprias e aptas a disciplinar as relações de trabalho em seus aspectos mais gerais.

Observe que o papel da CLT vai além da função de unificação das leis em um único instrumento jurídico, inserindo-se também na promoção de direitos e garantias iguais aos trabalhadores e uma maior segurança jurídica contra eventuais violações.

Dessa forma, a Consolidação das Leis Trabalhistas e os direitos trabalhistas afirmam importante marco histórico do direito do trabalho no Brasil ao reunir dispositivos de aplicação geral em um único instrumento legal.

\subsection{A Evolução das Relações de Trabalho no Brasil}

Trabalhada a Consolidação das Leis trabalhistas e os direitos trabalhistas, neste capítulo, será disciplinada a modernização das relações de trabalho e a necessidade de alterações na Consolidação das Leis Trabalhistas, inicialmente abordando a evolução das relações de trabalho no Brasil.

Segundo Vilela (2010), diferente dos países da Europa nos quais os direitos trabalhistas foram reivindicados pela mobilização da coletividade, no Brasil essa evolução história parte de processo oposto, de uma ação estatal para a coletividade produzindo diferentes efeitos que são vislumbrados até os dias atuais.

Neste sentido Júnior (2011) afirma que as relações brasileiras de trabalho teriam evoluído da escravidão operada perante os negros para uma forma de servidão, no qual o trabalho passa a ser assalariado.

E na ânsia de proteção a essas relações, destaca Silva que naquele momento histórico a legislação trabalhista visava reger de forma absoluta, de modo imperativo e categórico, não considerando válido o exercício da autonomia da vontade das partes (Empregador X Empregado), que decidissem sobre quaisquer dos direitos afetos ao exercício empregatício. Do mesmo modo, viu-se uma intensa produção de decretos que regravam uma atividade laboral em específico ou um determinado componente da relação empregatícia, a exemplos, a instituição da Carteira Profissional, a limitação da duração da jornada de trabalho para os que trabalham no comércio, nas 
indústrias, nas farmácias, nas casas de diversões, nas casas de penhores, nos bancos e casas bancárias, nos transportes, na educação, entre outros (Silva, 2012).

Denote que as relações de trabalho no Brasil evoluem de uma supressão de direitos e garantias estampada pela prática da escravidão para uma concessão pormenorizada e regrada por institutos e órgãos próprios preocupados com o assegurar o máximo de direitos com vistas a promoção da dignidade do trabalhador.

Portanto, a evolução das relações de trabalho no Brasil salienta a construção de direitos e garantias do trabalhador a partir de um longo e prejudicial processo de exploração do outro e no qual o Estado teve importante papel em sua concretização.

\subsubsection{Alterações na legislação trabalhista e as relações de trabalho: Uma necessidade iminente}

Comentada a evolução das relações de trabalho no Brasil e a importância da ação estatal em seu desenvolvimento, a seguir, serão tratadas as alterações na legislação trabalhista e as relações de trabalho: uma necessidade iminente.

E para compreender essa necessidade devem-se analisar argumentos ligados tanto a idade cronológica da Consolidação das Leis Trabalhistas e suas alterações, quanto o contexto global no qual está inserida a sociedade que a requer.

Versando sobre a CLT e sua idade cronológica, Trindade (2017a, 2017b) salienta que embora sua redação original já tenha sofrido inúmeras modificações ao longo dos anos é possível vislumbrar posicionamentos de que restaria ela ultrapassada e extremamente protecionista, atravancando o crescimento econômico e gerando desempregos.

Segundo Mattos (2017), ideias de flexibilizações das normas trabalhistas surgem diante dos avanços tecnológicos e das mudanças sociais que permitem com que o empregado desenvolva o serviço de qualquer lugar, bem como frente à crise econômica, a contratação de novos empregados e a redução de encargos trabalhistas.

Neste sentido, Andrighetto (2008), salienta que se deve observar o papel exercido pela globalização, a qual está intimamente ligada a flexibilização em sentido amplo, visto que é justamente dentro deste esquema que surge a necessidade de modificações administrativas, legislativas e de resolução de conflitos, tal como uma forma de salvar o desemprego ou forma de destruição do direito do trabalhador.

Além disso, o aumento do número de reclamações trabalhistas no país, sobrecarregando o Poder Judiciário, também apontou a necessidade de se rever à atual legislação trabalhista. Para se ter um exemplo, apenas no ano de 2016, o Brasil registrou mais de 3 milhões de novas ações trabalhistas, conquistando a primeira posição mundial em demandas judiciais envolvendo relações de trabalho (Mattos, 2017).

Atente-se que a ânsia por alterações no campo trabalhista surge num cenário caótico de crises econômicas, sociais e jurídicas como forma de resolução das mazelas enfrentadas pelo empregado e empregador.

Desse modo alterações na legislação trabalhista e as relações de trabalho como uma iminente necessidade advertem que as formas de trabalho ao se modificarem frente aos processos de tecnologia e globalização carecem de novas formas de proteção que assegurem direitos e garantias, sobretudo, da dignidade do trabalhador. 


\subsection{O cenário político social de inserção da Lei 13.467/2017}

Analisada a necessidade iminente de alterações na legislação trabalhista frente à modernização das relações de trabalho, neste capítulo, será disciplinada a lei $13.467 / 17$, e suas principais modificações no bojo da CLT, inicialmente, do cenário político social de sua inserção.

Segundo Britez (2017), a reforma trabalhista desenvolvida pela lei 13.467/17, surgiu em um cenário político adverso em que um presidente substituiu outro deposto do cargo por processo de impeachment somado a inúmeros escândalos políticos, baixa popularidade, em suma, um cenário caótico.

Para Biavaschi (2017), sem olvidar do rápido processo de tramitação de tal reforma considerando os efeitos, é importante ressaltar o contexto de recessão, de aumento de desemprego e ampliação de insegurança no mundo do trabalho.

Frise-se que ambos os autores são unânimes em atestar que o cenário político-social de inserção da reforma trabalhista destaca fragilidades políticas, sociais, econômicas, quanto medidas impopulares tomadas por um governo que aos olhos do povo não é bem visto.

De tal modo, o cenário político-social de inserção da lei $13.467 / 17$, é aquele que exprime o momento inadequado para se realizar reformas quer trabalhistas, ou em outros setores que aflijam de sobremaneira os direitos da população.

\subsubsection{Panorama geral das modificações na Consolidação das Leis Trabalhistas}

Compreendido o contexto político social de inserção da lei 13.467/17, como aquele desfavorável a promoção de tais alterações, a seguir, será tratado o panorama geral das modificações na Consolidação das leis trabalhistas.

Oriunda do projeto de lei 6.787, apresentado em 23 de Dezembro de 2016, a referida lei apresenta mudanças que atingem as três fontes do Direito do Trabalho: a lei, a sentença normativa da Justiça do Trabalho e a negociação coletiva. (Queiroz, 2017).

E não obstante seja impossível tratar de todas as mais de duzentas modificações e suas repercussões em um único artigo científico, é possível traçar resumidamente um panorama geral de seus objetivos, entre eles promover a:

(...) flexibilização de direitos trabalhistas previstos legalmente, resguardados apenas os que estão escritos na Constituição Federal; ampliação das possibilidades de terceirização e pejotização (contratação do trabalhador como pessoa jurídica e sem vínculo empregatício); criação de novas formas de contratação, especialmente o autônomo exclusivo e o intermitente; restrições de acesso à Justiça do trabalho; retirada de poderes, atribuições e prerrogativas das entidades sindicais; universalização da negociação coletiva sem o limite ou a proteção da lei (...) autorização de negociação direta entre patrões e empregados para redução ou supressão de direitos (Queiroz, 2017, p. 11-12).

Como se destaca em consonância aos argumentos de modernização das relações trabalhistas a reforma acaba por prestigiar dois perigosos pontos que podem acarretar sérios danos a estrutura judiciária e a parte mais fraca do contrato trabalhista: a flexibilização de direitos e a imputação da responsabilização das partes pela resolução do conflito.

Desse modo, o panorama geral das modificações na consolidação das leis trabalhistas salienta alterações que constituem entraves aos direitos e garantias do trabalhador, enquanto ser 
humano dotado de dignidade, ao invés de operar a tão sonhada modernização das relações de trabalho.

\subsection{Críticas e Contradições da Lei 13.467/2017}

Feita a abordagem do panorama geral das modificações na Consolidação das Leis Trabalhistas, neste capítulo, serão tratadas as contradições, críticas e eventuais pontos positivos da reforma trabalhista, preliminarmente, as críticas e contradições.

A maioria dos dispositivos descritos traz restrições no campo trabalhista, ou, os atualizam conforme entendimentos já consolidados em súmulas do Tribunal Superior do Trabalho e entendimentos minoritários (Trindade, 2017a, 2017b).

Na concepção de Queiroz (2017), pretendeu a lei legitimar a redução de direitos e a precarização das relações trabalho ao substituir o Direito do Trabalho pelo Direito Civil, sobretudo, em razão da retirada da legislação o caráter de norma de ordem pública e irrenunciável, por institucionalizar a prevalência do negociado sobre o legislado, permitir a contratação de serviços em lugar da contratação de empregados e autorizar a terceirização na atividade fim das empresas.

Neste diapasão quatro grandes falácias podem ser transcritas, a primeira no que tange a flexibilidade e redução de direitos sociais criarem novos empregos e aumentar a competitividade, visto que não há dados empíricos que comprovem tal façanha e os estudos promovidos pela Organização Internacional do Trabalho em 2015, sinalizam o contrário; a segunda, de que a legislação precisa ser modernizada, quando ela já foi toda reformada; a terceira, da insegurança jurídica e excessiva litigiosidade, quando as multas são baixas e os direitos desrespeitados, e por fim, a quarta, da reforma como negociado, sob argumentos de que fortalecerá o sindicato e que o empregado não precisará do Estado (Biavaschi, 2017).

A título de exemplos citam-se a diminuição do horário de almoço para 30 minutos, a demissão sem justa causa com recebimento de $80 \%$ do Fundo de Garantia por tempo de serviço e sem seguro desemprego, o fim das horas in itinere, a possibilidade da gestante trabalhar em ambiente insalubre, as custas processuais pagas pelo empregado em caso de perda da ação, o trabalho intermitente com férias sem remuneração, dentre outros.

Frise-se que as críticas e contradições da norma ultrapassam a ideia de rapidez no processo de feitura da norma e alcançam falsos argumentos de melhoria da qualidade de vida e de trabalho dos sujeitos.

Assim, as críticas e contradições da lei 13.467/17, ressaltam a precariedade da norma para promover a realização de modernização, flexibilização e garantia de direitos do trabalhador e empregador.

\subsubsection{Eventuais pontos positivos da Reforma Trabalhista}

Ponderada as críticas e contradições da lei 13.467/17, sobretudo, frente à redução de direitos e garantias do trabalhador, a seguir, serão disciplinados os eventuais pontos positivos da reforma trabalhista.

Para alguns doutrinadores a reforma trabalhista ressalta positividade ao conceber a possibilidade de divisão das férias em três períodos, no qual um deles não poderá ser menor que catorze dias, no assegurar a inegociabilidade do FGTS, $13^{\circ}$, e seguro desemprego, bem como frente ao fim da obrigatoriedade da contribuição sindical (Vilela \& Frischlander, 2017). 
Igualmente, fala-se em maior representatividade dos empregados nas empresas, liberdade na pactuação dos contratos de trabalho, oportunizando contratações que observem cursos e experiências diferenciadas, homologação dos acordos trabalhistas pela Justiça do Trabalho, entre outros benefícios (Vilela \& Frischlander, 2017).

Observe que o viés de tais pontos são a liberdade e a flexibilidade das relações de trabalho, ou seja, de que as partes pactuem de que forma, por quanto tempo e como será exercida essa relação sem todas aquelas amarras burocráticas da lei.

Dessa forma, eventuais pontos positivos da reforma trabalhista destacam a liberalidade das partes em consonância a boa-fé do empregador e dos direitos assegurados na Constituição de 1988.

\subsection{As empresas e os impactos produzidos pela Lei 13.467/2017}

Avaliados os impactos produzidos frente ao trabalhador, em sua grande maioria de cunho negativo e estritamente prejudicial, a seguir, se versará sobre os impactos frente as empresas.

Para Mattos (2017), ao alterar cerca de duzentos dispositivos da Consolidação das Leis trabalhistas a lei 13.467/17, visou favorecer claramente o empresário, suprimindo e reduzindo direitos dos empregados.

Neste diapasão é possível se vislumbrar efeitos favoráveis a partir da liberalidade concedida as partes na pactuação de contratos e na extinção dos mesmos, como salientado anteriormente, bem como no que tange a compensação das horas extras, nos menores custos para recorrer, na divisão das férias do empregado que faticamente diminuem os impactos causados por sua ausência. Ainda na retirada das horas in itinere que diminuem os gastos, no contrato intermitente que possibilita contratações para serviço em determinados períodos, na terceirização para fins de qualificação da mão de obra e redução de custos com contratação, dentre outros.

Neste diapasão Queiroz (2017), destaca no campo da liberalidade um elemento de pressão que antes os empregadores não detinham: o poder de chantagear os trabalhadores para forçar o sindicato ao acordo, alegando que se não concordarem com a redução de direitos poderão mudar a planta da empresa para outra cidade ou estado.

Para Pereira e Orsi (2017), dentre os impactos mais importantes da reforma que podem ser sentidos em face das empresas está o entendimento já consolidado no artigo 448 A, da CLT, que transcreve a responsabilidade do sucessor na sucessão de empresas ou empregadores e suas obrigações trabalhistas, inclusive as contraídas à época em que os empregados trabalhavam para a empresa sucedida. Porém, nos termos do parágrafo único do mesmo artigo, é possível estabelecer a responsabilidade solidária da empresa sucedida que responderá quando comprovada fraude na transferência, a exemplo, quando a aquisição for feita por empresa "laranja", apenas para afastar a responsabilidade trabalhista.

Destaque que diferente do empregado as empresas empregadoras de mão de obra poderão se utilizar da liberalidade para decidir as regras do jogo, vez que dispõem de objeto visado pelo trabalhador: o capital. Por óbvio não se pode deixar de ponderar que os altos custos para a regularização do empregado têm sua parcela de culpa na flexibilização dos direitos e eventuais distorções da legislação.

Assim, as empresas e os impactos produzidos pela lei 13.467/17, ressaltam inúmeros benefícios a figura das empresas empregadoras de mão de obra pela abertura da negociabilidade dos contratos e direitos previstos, sobretudo, pelo poder exercido pelo capital que detém. 


\subsection{Os sindicatos e a nova legislação trabalhista}

Compreendidos os impactos produzidos perante as empresas a par da edição da lei 13.467/17, que reformou a legislação trabalhista trazendo-lhes inúmeros benefícios, por derradeiro, serão tratados os impactos produzidos perante os sindicatos.

Segundo Pereira e Orsi (2017), uma das medidas de maior destaque na Reforma Trabalhista foi a extinção da contribuição sindical obrigatória, conhecida popularmente como "imposto sindical", antes cobrada de todos os integrantes da categoria (para os empregados, um dia de salário por ano; para os empregadores, um percentual de seu capital social).

Para Queiroz (2017), tal extinção traz o enfraquecimento do poder de ação das entidades sindicais de defesa das categorias, especialmente em razão da fragmentação da representação sindical via terceirização e pejotização; da prevalência da negociação sobre a lei e do acordo sobre a convenção, independentemente de ser ou não mais vantajoso para o trabalhador. Ainda da ampliação das possibilidades de negociação individual, a eliminação da ultratividade de acordo ou convenção, o fortalecimento da comissão representativa dos trabalhadores no local de trabalho em detrimento do sindicato, que perde atribuição e fica excluído do processo de organização da eleição dos representantes dos trabalhadores, levando-o, consequentemente, a asfixia financeira e dificuldade de acesso à Justiça do Trabalho.

Observe que o sindicato dentro da modernização proposta perde alguns de seus poderes no auxílio ao trabalhador, podendo igualmente ser submetido às vontades do empregador na realização de acordos que não são vantajosos para ele, quiçá para o empregado.

Assim, os sindicatos e a nova legislação trabalhista ressaltam que a reforma trabalhista promovida pela lei 13.467 , ao flexibilizar a sua atuação subtrai alguns de seus poderes na prestação de assistência ao trabalhador, reduzindo-o a atividades secundárias, sob argumentos falaciosos de que sem contribuição continuariam atuantes como antes.

\section{Procedimentos metodológicos}

Perpassada a revisão da literatura, a seguir, serão apresentados os procedimentos metodológicos utilizados para a consecução dos fins almejados pela pesquisa referente às alterações promovidas pela Lei $13.467 / 17$, na legislação trabalhista brasileira.

Por ser uma pesquisa pautada na discussão de texto legal e de cunho extremamente recente no seio social e legal, utilizou-se do método lógico-dedutivo, com respaldo em doutrinas e jurisprudências brasileiras, com vistas à apresentação dos efeitos negativos e positivos da Lei 13.467/17, que alterou a legislação trabalhista em inúmeros pontos.

O interesse pela temática surge em razão dos impactos sofridos pela classe trabalhadora frente à retirada de direitos de suma importância, sobretudo, pelo enfraquecimento dos sindicatos, enquanto defensores dos trabalhadores no âmbito extrajudicial e judicial.

No mais, analisou-se a evolução das relações de trabalho no Brasil, alguns pontos da legislação atual atinente, bem como os conceitos de trabalhador, empresas e sindicatos.

A pesquisa procurou trazer ainda alguns dados sobre a atualização legislativa e a sua fundamentação em súmulas já consolidadas pelo Tribunal Superior do Trabalho, entendimentos minoritários e estudos da Organização Internacional do Trabalho realizados em 2015, que já sinalizam a redução de direitos e o fracasso da dita modernização. 
Desse modo, os procedimentos metodológicos utilizados são de cunho lógico-dedutivo, com respaldo nas doutrinas e jurisprudências brasileiras, sobretudo, do Tribunal Superior do Trabalho.

\section{Apresentação e Discussão de Resultados}

Salientado o uso do procedimento metodológico lógico-dedutivo, com respaldo doutrinário e jurisprudencial, por fim, será elucidada a apresentação e discussão dos resultados.

A par das críticas e contradições ressaltadas pela lei 13.467/17, é possível denotar que seu objetivo precípuo, em tese, foi promover a modernização das relações trabalhistas no Brasil.

Nos pontos positivos ressaltados pelas doutrinas citadas é possível aferir uma maior liberdade na concretização das relações de trabalho, a par das flexibilidades nos horários e acordos entre patrão e empregado. A doutrina de Vilela e Frischlander (2017), neste sentido, ressalta a possibilidade de divisão das férias em três períodos, a inegociabilidade do FGTS, $13^{\circ}$, e seguro desemprego e o fim da obrigatoriedade da contribuição sindical.

Em contrapartida, nos pontos negativos, grandes falácias são apontadas no que tange aos efeitos que essa flexibilidade de direitos poderia produzir em um país como o Estado brasileiro, reduzindo direitos sociais fundamentais ao invés de promover a criação de novos postos de trabalho e concretizar a tão sonhada modernização.

O poder do negociado entre patrão e empregado, sobretudo, frente à reforma atinente aos sindicatos, gera insegurança jurídica e uma tendência a maior litigiosidade entre as partes. Neste diapasão Biavaschi (2017), cita quatro grandes falácias da reforma trabalhista, que foram previstas pela Organização Internacional do Trabalho em estudos promovidos em 2015, a primeira referente a não existência de dados que comprovem que a flexibilidade e a redução de direitos sociais criem novos empregos e aumente a competitividade, a segunda, da legislação precisar se reformada, quando essa já sofreu inúmeras modificações ao longo dos anos; a terceira, da insegurança e litigiosidade provocada pelas baixas multas e o desrespeito a direitos e a quarta, do negociado como fortalecedor da relação trabalhista.

Diante disso, seus efeitos são mais favoráveis as empresas, que detendo o poder monetário poderão forçar acordos e impor dadas obrigações em desrespeito aos direitos e garantias constitucionalmente previstas dos trabalhadores e sindicatos.

\section{Considerações Finais}

O presente trabalho é concluído ressaltando que sua pretensão não se voltou ao esgotamento do tema, mas a fornecer substratos para a compreensão dos impactos legais, sociais e econômicos promovidos pela reforma trabalhista para os trabalhadores, empresas e sindicatos.

Não obstante estejamos vivenciando uma modernização das relações de trabalho, a par da globalização e de outros elementos atrelados ao desenvolvimento humano, a Lei 13.467/17, ao se intitular como uma reforma trabalhista tendente a corrigir e ajustar direitos e garantias acabou por desencadear retrocessos e abrir brechas à formação de inúmeras demandas judiciais para a discussão da prevalência do negociado em detrimento da lei.

O trabalhador como parte mais fraca da relação de trabalho continua merecedor de proteção diferenciada frente ao poderio das empresas, necessitando inclusive da participação e força ativa dos sindicatos, sobretudo, frente a liberalidade concedida as partes. Os sindicatos exercem 
importante papel na defesa de seus direitos, quer auxiliando ou realizando acordos com os empregadores, funções que não podem ser esvaziadas de plano, sob pena de graves violações aos direitos e garantias.

As empresas, enquanto empregadoras de mão de obra, necessitam de alterações que diminuam os gastos com folha de pagamento e tributos atinentes, mas a liberalidade que podem exercer conjuntamente aos trabalhadores pode permitir imposições e injustiças pelo capital que detém. É preciso um bom senso e boa-fé por parte do empregador.

\section{Referências}

Andrighetto, Alessandro Lopes. (2009). Globalização e a flexibilização do Direito do Trabalho no Brasil. São Paulo: Clube do livro.

Biavaschi, Magda Barros. (2017). A Falácia da reforma trabalhista em andamento: propostas que retiram direitos e não criam emprego. Revista no mérito, 12(55), p. 4-10.

Britez, Sandro Gile. (2018). Algumas considerações acerca da lei 13467/17- reforma trabalhista.2017. Disponível em: <https://www.migalhas.com.br/dePeso/16,MI264260,71043Algumas+consideracoes+acerca+da+lei+1346717+Reforma+trabalhista $>$, Acesso em 10 Ago. 2018.

Ceneviva, Walter. (2003). Direito constitucional brasileiro. 3. ed. São Paulo: Saraiva.

Costa, Jeferson Alexandre. (2015). Breve Histórico do Direito de trabalho. Disponível em: <https://jeffersoncosta.jusbrasil.com.br/artigos/194061399/breve-historico-do-direito-dotrabalho-brasileiro>, Acesso em: 11.Ago.2018.

Marques, Paulo Edson. (2013). Apostilas Concurso Público Ministério do Trabalho e Emprego (MTE). São Paulo, Solução.

Mattos, Cibele Naoum. (2017). Reforma trabalhista: modernização ou retrocesso? Disponível em: $<$ https://www.migalhas.com.br/dePeso/16,MI265160,81042$\underline{\text { Reforma+trabalhista+modernizacao+ou+retrocesso }>, ~ A c e s s o ~ e m ~ 10 . A g o .2018 . ~}$

Pereira, Leone, \& Orsi, Renata. (2018). Direito Individual do Trabalho. In: Araújo Junior, Marco Antonio, \& Barroso, Darlan (Coords). Reta final OAB conteúdo complementar: Reforma Trabalhista. São Paulo, Thompson Reuters Brasil. Disponível em: $<$ https://livrariadamasio.com.br/conteudo_complementar/pdf/Encarte_Reforma_Trabalhista_Dir eito_do_Trabalho2.pdf $>$, Acesso em: 10 Ago. 2018.

Queiroz, Augusto (Org). (2017). Reforma trabalhista e seus reflexos sobre os trabalhadores e suas entidades representativas. Brasília: DIAP.

Silva, Cássia Cristina Moretto da Silva. (2012). A proteção ao trabalho na constituição federal de 1988 e a adoção do permissivo flexibilizante da legislação trabalhista no Brasil. Revista da Academia Brasileira de Direito Constitucional, 4(7), Jul/dez., p. 274-301.

Trindade, Rodrigo. (2017a). Reforma Trabalhista - 10 novos princípios do Direito Empresarial do trabalho. Disponível em: <http://www.amatra4.org.br/79-uncategorised/1249-reformatrabalhista-10-novos-principios-do-direito-empresarial-do-trabalho>, Acesso em: 11 Ago. 2018.

Trindade, Rodrigo. (2017b). Autonomia negocial é meio de esculhambar o meio ambiente de trabalho. Disponível em: <https://www.conjur.com.br/2017-abr-01/rodrigo-trindade-negociacaolivre-esculhambara-ambiente-trabalho>, Acesso em: 11 Ago. 2018.

Vilela, Fábio Goulart. (2010). Manual de Direito do Trabalho. São Paulo: Elsevier. 
Vilela, Peterson, \& Frischlander, Karina. (2017). Reforma trabalhista - pensemos nos pontos positivos. Disponível em: 〈https://www.jota.info/opiniao-e-analise/colunas/coluna-do-l-obaptista-advogados/reforma-trabalhista-pensemos-nos-pontos-positivos-03052017>, Acesso em: 11 Ago. 2018.

\title{
The Impacts of the labor reform for the workers, companies and unions: An analysis of the law 13.467/2017
}

\begin{abstract}
The purpose of this paper is to analyze the impacts of the labor reform promoted by Law 13467/17, for workers, companies and unions. For that, we use the logical-deductive method with support in doctrinal currents and jurisprudence on the subject. Impacts will be considered as legal, social and economic repercussions; worker, as an individual who provides services on a sporadic basis to a third party and for payment; companies, such as economic and social activities carried out by the entrepreneur, depending on the meeting of human, material and technical elements, and unions as an association that brings together individuals from the same economic or labor segment. By altering the Consolidation of Labor Laws (CLT), with a view to modernizing and easing labor relations in Brazil, Law 13,467 produced unfavorable impacts to workers and unions and favorable to companies, when by the liberality granted the parties allowed the agreement overlapping the law, leading to the suppression of legally stipulated rights and guarantees, as well as a real setback to labor legislation. The results of the study show that the prevalence of the negotiated between boss and employee to the detriment of the law and the loss of the power of the unions in the protection of the workers, subject the working class and the unions to the capital power belonging to the employers, without actually modernizing it the social requirements that Brazil longs for.
\end{abstract}

Keywords: Modernization of labor relations. Workers law consolidation. Flexibilization. Social rights. Human dignity.

\section{Sobre os Autores}

\section{Júlia Pottumati Nogueira ABDALA}

Especialista em Desenvolvimento \& Gestão de Pessoas. Centro Universitário Farias Brito, Rua Barão do Rio Branco, 2424, Centro, Fortaleza, CE, Brasil, CEP 60025-060.

E-mail: juliapottumati@hotmail.com

\section{Mauricio Johnny LOOS}

Pós-Doutor em Gestão Industrial. Professor do Centro Universitário Farias Brito, Rua Barão do Rio Branco, 2424, Centro, Fortaleza, CE, Brasil, CEP 60025-060.

E-mail: mauricioloos@hotmail.com 